\title{
Context, Entorn i Servei: l'aprenentatge mitjançant projectes, de les àrees científiques a la Interdisciplinarietat
}

\author{
Miriam Redondo (mredon6@xtec.cat) Institut Quatre Cantons (Barcelona) \\ Neus Ruiz (nruiz12@xtec.cat) Institut Marta Estrada (Granollers) \\ Sara Sánchez (ssanch39@xtec.cat) Institut Montserrat Colomer (Sant Esteve Sesrovires) \\ Rosa Solé (rsole125@gmail.com) Institut Montserrat Colomer (Sant Esteve Sesrovires) \\ Jordi Calvet (jcalvet@xtec.cat) Institut de Ciències de l'Educació de la Universitat Autònoma de Barcelona \\ Marta Caño (mcano226@xtec.cat) Institut de Cornellà (Cornellà)
}

El treball en contextos rellevants que proposa l'Aprenentatge Basat en Projectes, implica que, a més dels continguts científics, el projecte recluti continguts d'altres matèries. Aquesta interdisciplinarietat té una gestió complexa que, d'altra banda, permet projectes més connectats al món real. En aquest article, es descriuen 5 projectes de diferents àmbits de la ciència (astronomia, diversitat biològica, genètica, histologia) que s'han desenvolupat de forma interdisciplinària en funció de les necessitats $i$ oportunitats didàctiques de diversos contextos, incloent museus, criminologia, gestió d'espais urbans i col-laboració amb institucions externes.

Paraules clau: ABP, Interdisciplinarietat, Context, APS.

Project-Based Learning approaches in Science Education imply working in real contexts, and this need the work from several disciplines. The interdisciplinary approach is complex to develop but allows to construct projects with strong connections with the real world. In this article, we describe 5 projects from different science contents (astronomy, life diversity, genetics histology) that have been developed in a interdiscipinar frame following the needs and opportunities of several contexts, including museums, criminology, urban spaces administration and collaboration with other non-scholar institutions. .

Paraules clau: PBL, Interdisciplinar, Context, Service-Learning.

\section{INTRODUCCIÓ}

L'ensenyament té un impacte més fort en l'adquisició de competències quan es produeix en el marc de contextos rellevants. En aquest sentit, el marc del treball per projectes (ABP) i, en particular, la seva connexió amb l'Aprenentatge-Servei (APS) són un camp interessant per les possibilitats d'aprenentatge amb un enfocament globalitzat partint d'un mateix context.

Contextualitzar vol dir emmarcar els aprenentatges en situacions reals fent servir els continguts com a mitjà per trobar solucions, respostes o com a vehicles per entendre allò que passa o per formar-se un criteri. Les vies per apropar-se a l'autenticitat són dues: proposar situacions versemblants des de dins de l'escola, o proposar situacions autèntiques vinculades amb el món de fora de l'escola. Aquesta autenticitat es produeix perquè les situacions en les que s'aprèn són semblants en les que després es faran servir al llarg de la vida. Els contexts plantejats en aquests tipus de projectes, a més d'autèntics, són rics ja que permeten treballar de manera activa els conceptes, les seves relacions, els llenguatges o sistemes simbòlics propis i contemplen múltiples formes de representació.

En les situacions, reptes, encàrrecs, en els serveis plantejats o amb els productes a elaborar, 
l'alumnat desenvolupa tant habilitats pròpies del món escolar com del món "fora-escola" i, per tant, inserides en la realitat i relacionades amb les dimensions personal, social (com a ciutadà) o professional.

Al llarg dels projectes plantejats, els aprenentatges poden tenir un component científic, però al darrera poden tenir també un component social i fer demandes a altres matèries, promovent la interdisciplinarietat. Els aprenentatges són funcionals en tant que resolen un problema plantejat per "algú" que espera una resposta, una acció, un producte. Sovint l'alumnat es veu empès a treballar en equip per intervenir activament, ja sigui per aportar un servei o complir un encàrrec.

\section{DESCRIPCIÓ D’EXPERIÈNCIES}

\section{Projecte Illes Verdes (Marta Caño)}

La proposta s'emmarca en el plantejament de reptes a través de projectes o ABP per assolir els aprenentatges i la seva orientació a la transformació en els entorns educatius que ajuda a vèncer situacions desfavorides i desfavoridores (Trujillo, 2016a, 2016 b). El projecte "Illes verdes" s'ha desenvolupat el curs 2015-16 amb 45 alumnes de 1r d'ESO.
Els objectius del projecte són:

- Analitzar les zones verdes del barri i de la ciutat $i$ valorar-ne les funcions.

- Dissenyar i construir espais verds pel pati de l'institut.

- Dissenyar i muntar una exposició per donar a conèixer un espai verd del barri: els horts socials.

- Conèixer les espècies vegetals del Parc de Can Mercader i dissenyar un itinerari botànic virtual.

Cada àrea participa en el projecte des dels seus propis objectius d'aprenentatge vinculats a tasques concretes, tal com es detalla a la Taula 1.

La seqüència didàctica té bàsicament 4 blocs desenvolupats al llarg de 10 setmanes, dedicant 8,5 hores cada setmana.

- Bloc 1: Les zones verdes al barri i a la ciutat.

- Bloc 2: Les plantes com a éssers vius de les zones verdes.

- Bloc 3: Donem a conèixer les nostres zones verdes (Itinerari botànic a Can Mercader i Exposició dels horts socials).

- Bloc 4: Dibuixem la nostra idea.

- Bloc 5: Construcció d'un Jardí Vertical.
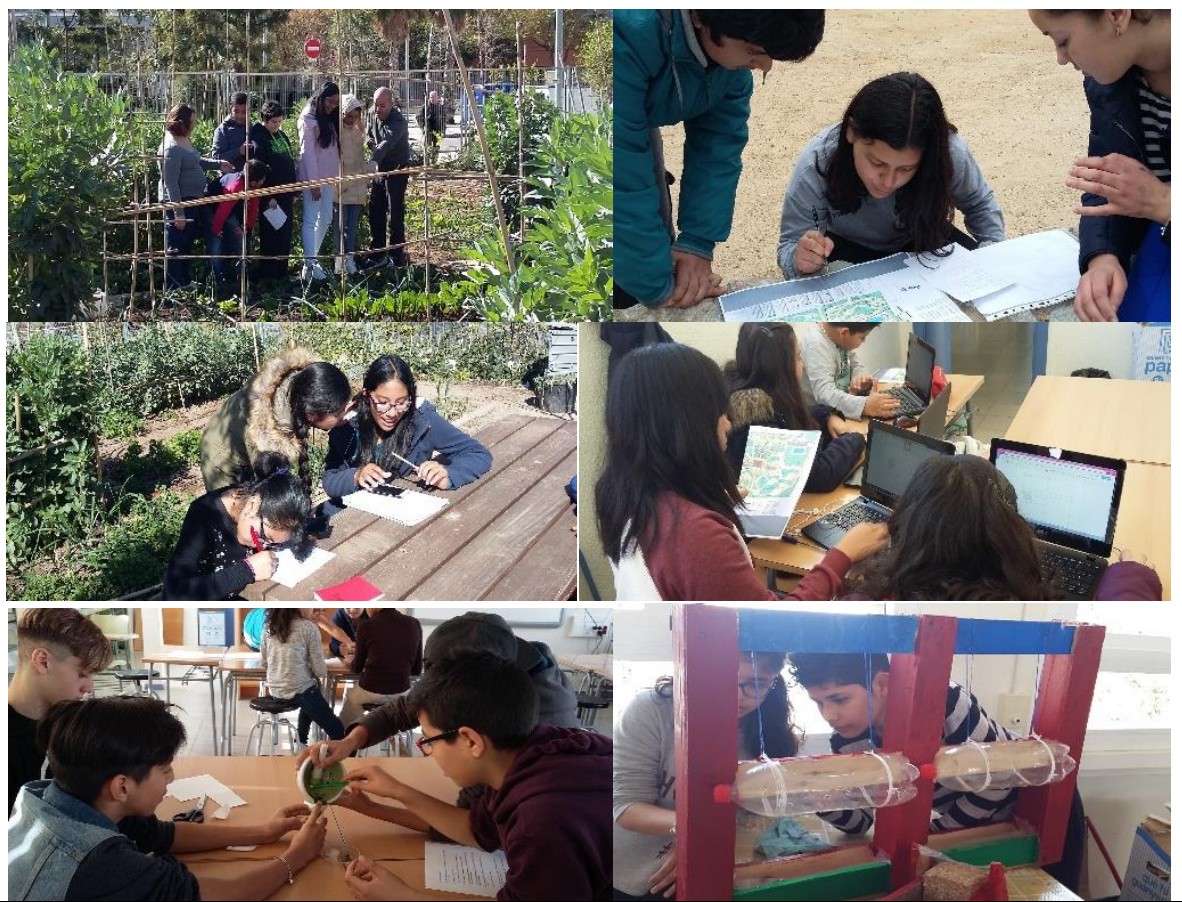

Figura 1. Alumnes de l'Institut de Cornellà visitant els horts socials de Sant Ildefons i preparant el itineraris botànics el Parc de Can Mercader, comprovant les hipòtesis al voltant de les plantes i construint horts urbans. 


\begin{tabular}{|c|c|c|}
\hline Àrea & Objectius d'aprenentatge & Tasques \\
\hline $\begin{array}{l}\text { Ciències } \\
\text { Naturals }\end{array}$ & $\begin{array}{l}\text { Conèixer el funcionament de les plantes com a éssers vius. } \\
\text { Aprendre a identificar espècies vegetals comunes a les zones } \\
\text { verdes de les ciutats. } \\
\text { Introduir-se al mètode científic: emissió d'hipòtesi, comprovació } \\
\text { i conclusions a través d'experiments. }\end{array}$ & $\begin{array}{l}\text { Experiments per comprovar que les plantes són éssers vius i fan les } \\
\text { funcions vitals } \\
\text { Identificació de diferents espècies vegetals del parc de Can Mercader } \\
\text { a través d'un itinerari. } \\
\text { Disseny d'un itinerari virtual botànic pel parc de Can Mercader. }\end{array}$ \\
\hline $\begin{array}{l}\text { Ciències } \\
\text { Socials }\end{array}$ & $\begin{array}{l}\text { Valorar el canvi d'usos del sòl al llarg del temps } \\
\text { Valorar les zones verdes i analitzar-ne les seves funcions a les } \\
\text { ciutats. }\end{array}$ & Comparar imatges de Cornellà al llarg de la història. \\
\hline $\begin{array}{l}\text { Tecnolo- } \\
\text { gia }\end{array}$ & $\begin{array}{l}\text { Introduir-se als sistemes de representació normalitzats. } \\
\text { Utilitzar instruments de representació gràfica aplicant, acotaci- } \\
\text { ons, escales i sistemes de representació normalitzats per a } \\
\text { representar objectes } \\
\text { Projectar i construir objectes senzills, tot aplicant el procés tec- } \\
\text { nològic. }\end{array}$ & $\begin{array}{l}\text { Dissenyar una jardinera pel pati. } \\
\text { Omplir el quadern d'equip amb el procés constructiu de la jardinera }\end{array}$ \\
\hline $\begin{array}{l}\text { Educació } \\
\text { Visual I } \\
\text { plàstica }\end{array}$ & $\begin{array}{l}\text { Conèixer les principals característiques del llenguatge fotogrà- } \\
\text { fic. } \\
\text { Conèixer els principals recursos de composició d'imatges i text. }\end{array}$ & $\begin{array}{l}\text { Fer fotografies durant l'entrevista als usuaris dels horts socials de } \\
\text { Sant Ildefons. } \\
\text { Dissenyar els plafons de l'exposició sobre els horts socials. }\end{array}$ \\
\hline Llengua & $\begin{array}{l}\text { Conèixer les característiques de l'entrevista. } \\
\text { Elaborar una entrevista amb intenció comunicativa. }\end{array}$ & $\begin{array}{l}\text { Dissenyar una entrevista per fer als usuaris dels horts socials de Sant } \\
\text { Ildefons. } \\
\text { Transcriure l'entrevista i fer una síntesi per a l'exposició sobre els } \\
\text { horts urbans. }\end{array}$ \\
\hline $\begin{array}{l}\text { Matemàti- } \\
\text { ques }\end{array}$ & $\begin{array}{l}\text { Aprendre a calcular percentatges a partir de dades reals de } \\
\text { l'entorn. } \\
\text { Extreure conclusions a partir dels percentatges }\end{array}$ & $\begin{array}{l}\text { Mesurar en un plànol del barri i de la ciutat la superfície de zones } \\
\text { verdes i comparar-la amb la total. } \\
\text { Calcular la superfície de zones verdes per habitant al barri i a la ciutat } \\
\text { i comparar aquesta dada amb les recomanacions de la OMS. }\end{array}$ \\
\hline
\end{tabular}

Taula 1. Objectius d'aprenentatge del projecte "Illes Verdes" per àrees i tasques associades.

Els dos grups de 1r d'ESO van fer el Bloc 1, però després, per tal de poder treballar còmodament al taller es van fer dues seqüències diferents. Un grup es va dedicar a fer uns dels encàrrecs - l'itinerari botànic virtual i l'exposició - i, per això, van desenvolupar els Blocs 2 i 3 . Mentrestant, l'altre grup va fer l'altre encàrrec del projecte - la construcció de jardineres pel pati - desenvolupant els Blocs 4 i 5 . Després, els grups es van intercanviar els encàrrecs. El treball cooperatiu es va desenvolupar en grups de 4 on cada alumne tenia un càrrec a desenvolupar dins de cada encàrrec. La planificació i repartiment de tasques es fa a través del Quadern d'equip. Són disponibles per a la seva consulta exemples de Quadern d'Equip [1].

L'avaluació té en compte els següents criteris:

- Realització de les tasques de cada Bloc del Moodle.

- Elaboració del quadern d'equip (en grup).

- Evidències d'aprenentatge i reflexió a la carpeta d'aprenentatge (individual).

- Producte final $i$ treball en equip.

\section{L'exposició museística i el congrés científic (Neus Ruiz)}

Les dues propostes presentades a continuació són dues aproximacions metodològiques al treball de les ciències com a eix vertebrador des d'una perspectiva multidisciplinària i s'han realitzat durant el curs 2015-16 com a projecte Globalitzat Trimestral amb 60 alumnes de $1 \mathrm{r}$ d'ESO de l'Institut Marta Estrada (Granollers, Barcelona) i s'estan duent a terme per segona vegada durant el curs 2016-17. Ambdues propostes que, en principi, treballen per un objectiu científic, tenen una perspectiva més globalitzada en el moment en què les diferents disciplines troben oportunitats per desenvolupar aprenentatges en els alumnes d'una manera coherent i connectada al propi objectiu. És a dir, es treballa a dos nivell didàctics. Per una banda, planificant, desenvolupant i comunicant una investigació per Equips d'Investigació. I, per altra banda, els mateixos alumnes s'organitzen en Comissions per a l'organització del propi esdeveniment (congrés, exposició) en aspectes logístics, organitzatius, de difusió, etc. Els materials per al desenvolupament d'aquests projectes són disponibles per a la seva descàrrega [2]. A nivell 
organitzatiu, en cada projecte es participa des de vàries matèries en les seves hores de classe al llarg del trimestre i, segons les necessitats a finals de trimestre, s'alliberen dies sencers de classe.

En el projecte $X Y Z$ Stars els alumnes reben l'encàrrec de crear o organitzar una exposició astronòmica al Museu de Ciències de Granollers. Com a part de l'encàrrec, els alumnes s'organitzen per equips, participant en la creació de diversos productes col-lectius vinculats a branques del projecte: el Solar System Pathway i l'exposició XYZStars. D'una banda, al Solar System Pathway es proposa als alumnes la construcció d'un passeig-maqueta urbana que representi el Sistema Solar (des del Sol al Cinturó de Kuiper) en un recorregut urbà de 10 km, de manera que en aquest itinerari, el passejant parteix de l'inici (representat per el Sol) i es troba al llarg del recorregut els diversos planetes ubicats al Iloc que ocuparien i representats en un panell físic a la mida que tindrien. Cada panell conté a més un codi QR que condueix a una descripció divulgativa sobre el planeta creada per els alumnes ubicada en una pàgina web creada ad hoc. Les produccions dels alumnes són disponibles per a la seva consulta a la web del projecte: http://solarsystempathway.museugranollersciencies.org/.

En aquest projecte els alumnes treballen els continguts d'astronomia, de càlcul de proporcions, manipulació de materials i competència lingüística, a més d'aspectes relacionats amb l'Autonomia i Iniciativa personal en el muntatge i organització de la inauguració que inclou l'elaboració dels discursos d'obertura, la distribució de les responsabilitats organitzatives de l'acte (acollida, guia, comissari) i la difusió entre les escoles de Primària i Secundària (Domènech et al., 2016).

Per la seva banda, el Earth Fluids Scientific Congress és un Projecte d'Investigació que aplica també metodologies d'ABP i Ensenyament de les Ciències Basat en la Indagació (ECBI), seguint els projectes d'Indagació (Domènech-Casal, 2017) perquè existeix una pregunta o objectiu extern amb l'aprenentatge; s'usen metodologies investigadores (disseny d'experiments, modelització, etc.); es treballa en equip i mitjançant la discussió a partir de les evidències; es genera un producte final col-lectiu en format científic i existeix un context que instrumentalitza i connecta el currículum amb el món real. El congrés científic treballa el procés d'investigació al voltant d'un tema tan general com és el de les capes fluides de la Terra - atmosfera i hidrosfera - però concretant en petites investigacions que els mateixos alumnes proposen i realitzen de principi a fi a partir d'espais del seu propi entorn. L'objectiu d'aprenentatge que es proposa és sobretot de caire procedimental - introduir els alumnes en la metodologia científica, l'anàlisi crític dels resultats i la comunicació científica -, però també conceptual - els cicles biogeoquímics i les problemàtiques de contaminació. Des de diferents matèries es fan aportacions significatives, en la representació de gràfics (Matemàtiques), l'elaboració d'abstracts (Anglès) i la competència lingüística (Llengua).

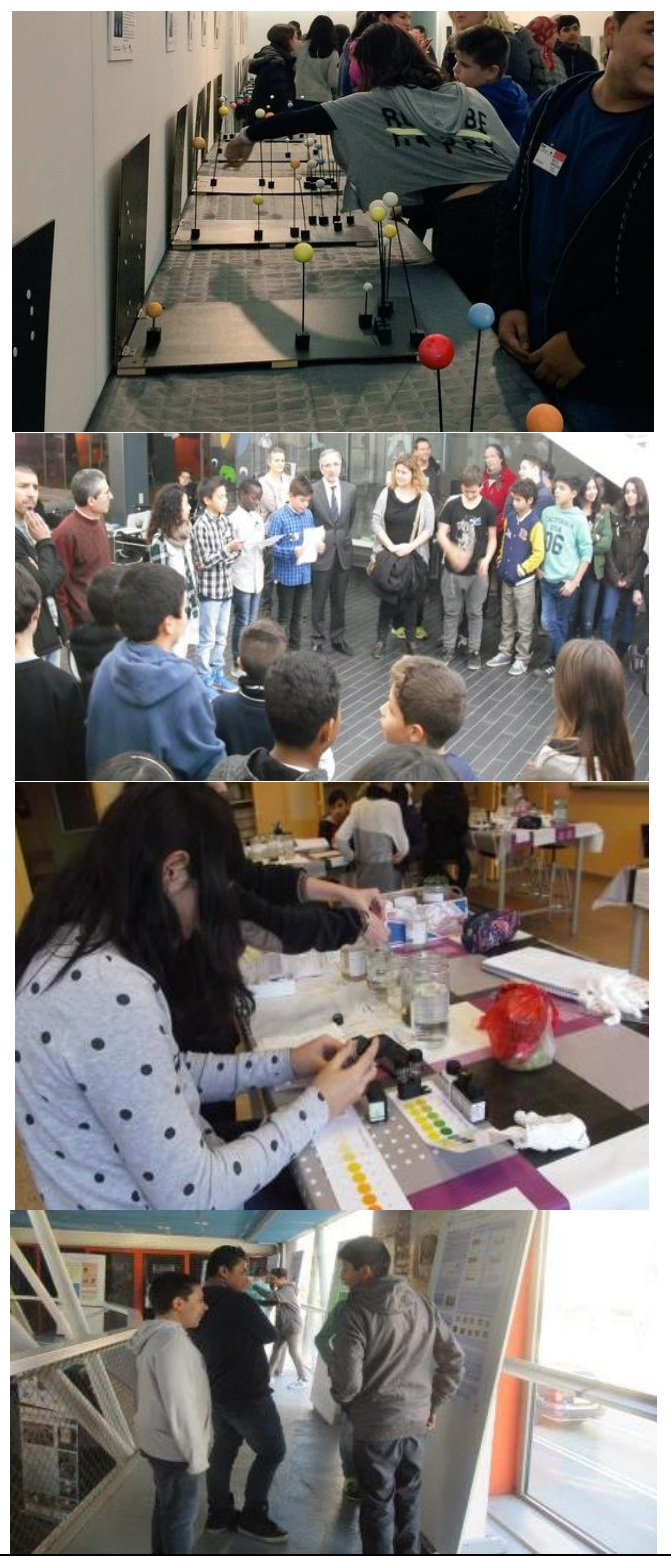

Figura 2. a) Maquetes de les constel-lacions principals del projecte $X Y Z S t a r s$ b) Inauguració de l'exposició XYZStars al Museu el curs 2015-16. c) Treball al laboratori per a l'Earth Fluids Scientific Congress. d) Sessió de pòsters durant el Congrés. 
La proposta s'estructura a dos nivells didàctics que treballen en paral-lel tots els alumnes (Llorente et al., 2017):

a) Els "Equips d'Investigació" encarregats de dissenyar l'experiment, recollir les mostres, analitzar-les, extreure resultats, establir conclusions i elaborar un pòster científic.

b) Les "Comissions d'organització" encarregades de preparar l'esdeveniment en les diferents àrees: dissenyar el logotip del congrés $i$ les invitacions, gestionar els espais, els horaris i el programa del congrés, encarregar-se de la logística, de les relacions públiques, buscar patrocinadors pel coffee-break, elaborar els tríptics informatius, buscar els ponents, elaborar els discursos d'obertura, tancament $\mathrm{i}$ presentació dels parlamentaris i encarregarse de la comunicació per realitzar la difusió externa, així com de la seguretat i de la tasca de "chairmans".

\section{Encàrrecs externs: entorn i servei (Jordi Calvet i Míriam Redondo)}

Aquesta proposta s'emmarca en els Encàrrecs Externs, on els alumnes reben propostes des de fora de l'Institut, connectades amb aspectes del currículum. S'han dut a terme diverses propostes, que s'han desenvolupat a l'Institut Quatre Cantons (Barcelona). Els encàrrecs que s'han rebut són molt diversos:

1) El Servei Bibliogràfic de l'ONCE encarrega una adaptació d'un conte per a persones invidents ( $2 n$ i $3 r$ d'ESO) pel que es fa necessari entendre quines capacitats $i$ vivències tenen les persones invidents o amb baixa visió. Això implica identificar i caracteritzar els sistemes físics i químics des de la perspectiva dels models, per comunicar i predir el comportament dels fenòmens naturals. En concret, tracta continguts del currículum de Ciències de l'ESO: la llum, la seva propagació, la formació de la visió. Tanmateix, també es relaciona amb la competència artística que parla de representar amb formes bidimensionals i tridimensionals o bé desenvolupar projectes artístics disciplinaris o transdisciplinaris tant personals com col-lectius.

2) El Centre d'Atenció Primària (CAP) del barri encarrega un estudi conèixer el perfil de l'adolescent del Poblenou amb tres indicadors diferents: els hàbits alimentaris; el consum de tòxics, i les relacions sexuals i afectives (4t d'ESO).

3) El Grup Cooperatiu TEB de persones joves amb discapacitat demanen nous dissenys per fabricar objectes decoratius o d'utilitat per a la vida diària per després comercialitzar-los.
4) La fundació Uszheimer encarrega el disseny d'un conjunt d'activitats pròpies de l'estimulació multisensorial que complementin l'estimulació cognitiva adreçades a persones afectades per dèficit de la funció cognitiva i/o demència en estadis inicials que ja realitza als centres de dia d'aquesta fundació.

5) L'Institut de Recerca del Vall d'Hebron (IRVH) van encarregar a l'alumnat de $1 \mathrm{r}$ de Batxillerat crear un ball per difondre una tesi doctoral sobre el càncer d'ovari. L'objectiu extern estava estretament relacionat amb la necessitat d'aquesta entitat de fer divulgació de la seva activitat de recerca

Posem com a exemple, el darrer dels encàrrecs. El context es presenta d'entrada clarament multidisciplinari però amb un pes important científic. Alhora, l'encàrrec pren una forma tan propera als adolescents que els enganxa a la primera: ens demanen una coreografia (cançó, ball, vídeo) de la tesi doctoral d'una biòloga per a presentar-la en un concurs de Science.

Per entendre la tesi sobre el càncer d'ovari van ser necessàries posar en joc moltes competències científiques. Era intrínsecament necessari entendre què deia aquesta tesi per poder-la convertir en una cançó cantada en anglès i coreografiada. Organitzar això amb un grup de 12 alumnes de batxillerat va promoure totes les competències que es puguin imaginar: per organitzar-se, per escollir, per consensuar, per poder imaginar un ball que expliqui, per poder narrar una història, per versionar una cançó $i$ cantar-la en anglès. En resum, eren presents els continguts i aprenentatges propis de la Biologia i Medicina, però també de Música, Anglès, com ara la Competència comunicativa, la Competència artística, la Competència social i ciutadana,...

Amb la realització d'aquest projecte es van assolir competències pròpiament científiques com:

- Comprendre les característiques químiques i les propietats de les biomolècules bàsiques que configuren l'estructura cel-lular per interpretar la seva funció en els processos biològics.

- Comprendre el paper dels àcids nucleics en la regulació del cicle cel-lular.

- Identificar les fases del cicle cel-lular i reconèixer la disfunció en les cèl-lules canceroses.

- Prendre actituds associades al treball científic, com la recerca d'informació, la capacitat crítica, el qüestionament d'allò que sembla obvi i l'actitud oberta a noves dades i especialment el treball en equip. 
- Aplicar i comunicar els coneixements, amb l'ajuda de les tecnologies de la informació i la comunicació, en relació amb la salut i la malaltia.

\section{S’ha escrit un Crim (Sara Sánchez i Rosa Solé)}

L'experiència es va realitzar el curs 2015-16 amb 90 alumnes de $3 r$ d'ESO i respon a la necessitat, i alhora a la motivació per començar un treball per projectes (Xarxa de Competències Bàsiques, 2015). Es tracta d'un treball compartit i multi-disciplinari però sense canviar els horaris ni dedicar una franja horària específica a fer el projecte. És així, doncs, un primer pas en què els professors i els alumnes hi participen en la seva hora/matèria. Els materials del projecte poden consultar-se al bloc: http://blocs.xtec.cat/xcbprojecte21/.

El tema principal i la línia conductora del projecte, utilitzada com a element impactant i motivador per als alumnes, és una notícia apareguda a la premsa diària que informa que s'ha trobat un cadàver d'un home al nostre institut. Això, acompanyat amb que els alumnes en entrar al centre al matí es trobin amb una zona acordonada a l'institut i la presència de la Policia Local.

Tot l'alumnat de $3 r$ d'ESO és adreçat a la cantina del centre on uns agents de la policia local els presenten el cas i els exposen quin és el procediment que se segueix en aquesta tipologia de casos, demanant als alumnes la seva col-laboració en la investigació.

A partir de grups d'investigació (de 4 alumnes) s'inicia un procés composat per diverses tasques amb la finalitat d' ajudar a la policia a esbrinar què és el que ha passat i resoldre el crim. Per tant, cada grup ha de donar una hipòtesi factible dels fets que concordi amb les conclusions realitzades a partir de les proves proporcionades i dels testimonis.

Les àrees que participen del projecte són: Visual i plàstica, amb tasques relacionades amb l'elaboració de retrats robot dels sospitosos a partir de les descripcions dels testimonis; Ciències Socials, amb tasques relacionades amb la pobresa i riquesa i el tercer món, per esbrinar el nivell socioeconòmic de la víctima; Economia, per esbrinar com podria haver passat l'individu de ric a pobre; Anglès, treballant vocabulari específic sobre investigacions criminals i novel-la policíaca i la redacció del producte final; i Biologia, per treballar la part d'investigació científica. En concret, des de l'àrea de Biologia es treballa l'estudi de l'aparell circulatori humà i la sang. A partit d'unes mostres de líquid vermell hauran d'esbrinar si es tracta de sang o no. Prèviament han d'investigar què és la sang i quins són els seus components i característiques, un treball repartit en tres tasques de tipologia individual i grupal.

Després de valorar diferents opcions i tenint en compte les matèries implicades, es dona a l'alumnat la opció de triar entre dos productes finals:

- L'elaboració d'un còmic en format foto-novel-la.

- La gravació en format vídeo d'una escenificació del crim.

Els dos productes finals han de reflectir el que creuen que ha passat, d'acord a les conclusions a les quals han arribat a partir de la investigació que cada grup ha realitzat. El producte final es presenta en llengua anglesa.

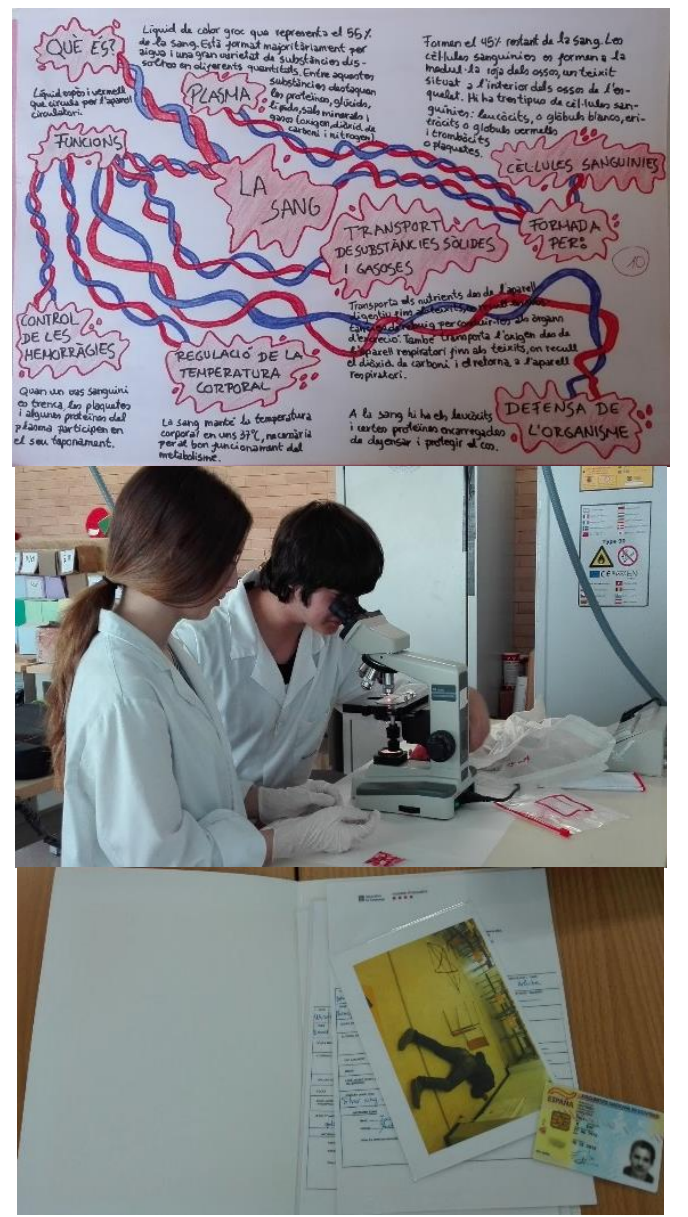

Figura 4. a) Mapa mental de la Tasca 2 (Biologia). b) Un equip fent una anàlisi de proves. c) Imatges de les proves i l'escena del crim.

Des de cada àrea que participa en el projecte, al llarg de la realització de les diferents tasques, es disposa de diferents elements d'avaluació (Sanmartí, 
2010) com les rúbriques de treball de grup, la coavaluació o el treball individual. Amb aquestes eines el professor de cada àrea qualifica a l'alumne amb una nota d'àrea que conta un percentatge dins el projecte, on a més a més es comptabilitza la trajectòria com a grup, en general, i el producte final.

\section{CONCLUSIONS}

Pensem que en aquests projectes, la presència d'un context, o encàrrec extern promou aprenentatges significatius, ja que l'alumnat ha de donar resposta a una necessitat real, plantejada per professionals d'algun sector determinat. Això implica una atenció i una exigència cap al producte final especials. L'alumnat té la necessitat (i l'oportunitat) de conèixer de primera mà el context que ha generat la problemàtica plantejada per l'entitat. A partir d'aquesta necessitat aprèn i s'autoregula per aconseguir satisfer-la.

En aquests contextos existeix un objectiu extern (i concomitant) a l'aprenentatge, existeix un context i un conflicte que instrumentalitza el currículum, s'usen metodologies actives $i$ treball en comunitat d'aprenentatge i es genera un producte final. El treball amb situacions contextualitzades aporta apropament i contacte amb una realitat concreta, motivació, implicació i major tensió per a l'estudi d'aquesta realitat, exigència i qualitat en el producte o servei, contacte amb el món professional o social, facilitat d'accés a informació diferent a la que poden trobar als llibres o a Internet i projecció a l'exterior i contactes per posteriors projectes. La seva relació amb un encàrrec concret aporta empatia vers a qui va adreçat, investigació i recerca per adquirir nous coneixements, abordar problemes complexos de manera globalitzada, passar de la dimensió individual a la col-lectiva (d'equip), autoregular-se per aconseguir l'objectiu final (avaluació), incloure proves, prototips i avançar.

En la revisió dels projectes hem identificat alguns aspectes d'utilitat en el treball per projectes interdisciplinaris:

- Tenir un espai setmanal d'una hora per coordinar-nos el professorat implicat és important per al treball interdisciplinari.

- El quadern d'equip [1] amb el repartiment de càrrecs en el grup, amb el diari de les sessions per a la planificació i avaluació dels grups és una bona eina per ajudar-los a treballar col-laborativament i guanyar autonomia.

- Ser dos professors a l'aula permet acompanyar a l'alumnat, especialment el que té dificultats.
- Cal aprofitar les oportunitats que ofereix el context per a la participació de matèries.

- Cal reservar espais setmanals a la regulació i estructuració de continguts per atendre a la diversitat. Una proposta seria dedicar-hi la sessió dels divendres i incloure la carpeta d'aprenentatge de l'alumnat per tal que anés reflexionant sobre el seu procés d'aprenentatge.

- L'avaluació del projecte es fa globalment, no per matèries. Tot i així, es pot dividir la qualificació en les diferents matèries segons les tasques de cada una a l'avaluació final.

- Valorem positivament la participació d'experts en temes relacionats amb el context o procediments del projecte.

- Quan els grups són heterogenis, cal vigilar que tots els components del grup treballin en funció de les seves possibilitats i mirar de treure el màxim de rendiment.

- Cal que els alumnes es responsabilitzin de guardar el material del grup, conservar-lo i portar-lo en el moment que calgui, altrament poden deixar al grup sense poder treballar alguna jornada.

- El producte final ha de concordar amb tota la feina prèvia i el context proposat, també en els seus formats.

- El temps ha d'estar ben ajustat i estipulat. Cada grup ha d'anar avançant en funció de les seves tasques.

\section{AGRAIMENTS}

Aquest article recull el contingut de les ponències de les Jornades sobre Aprenentatge Basat en Projectes \#STEMABP [https://stemabp.wordpress.com/], organitzades pel CESIRE del Departament d'Ensenyament i la Fundació Catalana per la Recerca i la Innovació. Els autors agraïm al professorat i alumnat dels centres la seva participació i a Jordi Domènech la tasca d'edició de l'article. Agraïm també el recolzament de les institucions externes i la Xarxa de Competències Bàsiques del Departament d'Ensenyament l'acompanyament en el Treball per Projectes

\section{REFERÈNCIES}

DOMĖNECH, X, LLORENTE, I, RUIZ, N., SERRA, C., ULLDEMOLINS, M., ARRIZABALAGA, A., DOMĖNECH-CASAL, J. (2016). XYZ-Stars i Solar System Pathway: una experiència museística de treball per projectes sobre les constel/acions i el Sistema Solar. Revista Ciències 31, 21-28.

DOMÈNECH-CASAL, J. (2017, en avaluació). Treball per projectes $i$ competència científica: una 
proposta metodològica per al disseny de Projectes d'Indagació. Perspectiva Escolar, en avaluació.

LLORENTE, I., DOMÈNECH, X., RUIZ, N., SELGA, I., SERRA, C., DOMĖNECH-CASAL, J. (2017). Un Congreso Científico en secundaria: articulando el Aprendizaje Basado en Proyectos y la indagación científica. Investigación en la escuela (acceptat).

SANMARTÍ, N. (2010). Avaluar per aprendre. Generalitat de Catalunya. Departament d'Educació.

TRUJILLO, F. (2016a).Educ@conTIC. A favor del Aprendizaje basado en Proyectos. [http://www.educacontic.es/blog/favor-del-aprendizaje-basado-en-proyectos-ftsaez].

TRUJILLO, F. (2016b).Educ@conTIC. Contra el Aprendizaje basado en Proyectos. [http://www.educacontic.es/blog/contra-el-aprendizaje-basado-en-proyectos-ftsaez].

XARXA DE COMPETÈNCIES BÀSIQUES (2015). Full d'indicadors per a l'ensenyant, És competencial aquesta unitat didàctica? Treball per projectes. Departament d'Ensenyament, Generalitat de Catalunya.

\section{NOTES}

[1] Quadern d'Equip per al Jardí Vertical: http://bit.ly/2mQ5COa ; Quadern d'Equip d'Itineraris: http://bit.ly/2mQ5COa

[2] Materials dels projectes $X Y Z S t a r s: ~ h t t p s: / / s i-$ tes.google.com/site/xyzstarsexhibition/home; Solar System Pathway: https://sites.google.com/site/solarsystempathway/home; Earth Fluids Congress: https://sites.google.com/site/airwatercongress/ 